\title{
2.3 Long-term efficacy and safety of infliximab plus methotrexate for the treatment of polyarticular course juvenile rheumatoid arthritis (JRA): Findings from an open-label treatment extension
} N Ruperto*1, DJ Lovell2 ${ }^{2}$ R Cuttica ${ }^{3}$, P Woo ${ }^{4}$, G Espada5 , C Wouters ${ }^{6}$, ED Silverman7 , Z Balogh ${ }^{14}$, M Henrickson ${ }^{15}$, J Davidson ${ }^{8}$, I Foeldvari ${ }^{9}$, L Imundo $^{10}$, G Simonini ${ }^{11}$, J Oppermann ${ }^{12}$, YK Shen ${ }^{13}$, S Visvanathan ${ }^{13}$, A Fasanmade ${ }^{13}$, A Mendelsohn ${ }^{13}$, A Martini ${ }^{1}$, EH Giannini ${ }^{2}$ and for the Paediatric Rheumatology International Trials Organisation (PRINTO) and the Pediatric Rheumatology Collaborative Study Group (PRCSG Study)

Address: ${ }^{1}$ IRCCS G Gaslini, Pediatria II - PRINTO, Genova, Italy, ${ }^{2}$ Cincinnati Children's Hosp Med Center, Cincinnati, USA, ${ }^{3}$ Hosp de Pediatria Dr Pedron de Elizalde, Buenos Aires, Argentina, ${ }^{4}$ Great Ormond St Hosp, London, UK, ${ }^{5}$ Hosp de Ninos Ricardo Gutierrez, Buenos Aires, Argentina, ${ }^{6}$ U Hosp Gathuisberg, Leuven, Belgium, ${ }^{7}$ Hosp for Sick Children, Toronto, Canada, ${ }^{8}$ Royal Liverpool Childrens NHS Trust, Liverpool, UK, ${ }^{9}$ Eilbek Clinic, Hamburg, Germany, ${ }^{10}$ Columbia/NY Presbyterian Hosp, New York, USA, ${ }^{11}$ U Florence, Firenze, Italy, ${ }^{12}$ Kinderklinik, Cottbus, Germany, ${ }^{13}$ Centocor R \& D, Inc, Malvern, USA, ${ }^{14}$ National Inst Rheuma \& Physiotherapy, Budapest, Hungary and ${ }^{15}$ Children's Hospital, Oklahoma City, USA

* Corresponding author

from 15th Paediatric Rheumatology European Society (PreS) Congress London, UK. 14-17 September 2008

Published: 15 September 2008

Pediatric Rheumatology 2008, 6(Suppl I):S3 doi:I0.I I86/I546-0096-6-SI-S3

This abstract is available from: http://www.ped-rheum.com/content/6/SI/S3

(C) 2008 Ruperto et al; licensee BioMed Central Ltd.

We report long-term safety \& efficacy of infliximab (IFX)+ methotrexate (MTX) treatment in JRA patients. In an international, multicenter, randomized, double-blind study, 122 children w/active polyarticular JRA despite prior MTX therapy received MTX plus a 3-dose induction (wks 0, 2, 6) of IFX $3 \mathrm{mg} / \mathrm{kg}$ through wk 44, or placebo (PBO) for 14 wks followed by IFX $6 \mathrm{mg} / \mathrm{kg}$ (wks 14, 16, 20, \& then q8 wks) through wk 44. Patients completing treatment through wk 44 were eligible to enter an open-label extension (OLE) of IFX $3 \mathrm{mg} / \mathrm{kg}$, beginning at wk 52 \& continuing $\mathrm{q} 8$ wks through wk 196. All patients continued with concomitant MTX. Physicians could increase or decrease the IFX dose by $\leq 1.5 \mathrm{mg} / \mathrm{kg} /$ infusion q8 wks, up to $6 \mathrm{mg} /$ $\mathrm{kg}$ or down to $3 \mathrm{mg} / \mathrm{kg}$, based on clinical response. Primary endpoint was the proportion of patients meeting ACR-Pedi-30, defined as improvement of $\geq 30 \%$ in $\geq 3$ of 6 core variables, $\& \leq 1$ of the remaining variables worsened by $>30 \%$. Remission was defined as 0 joints with active arthritis, normal ESR, \& physician's global assessment $\leq 10$ $\mathrm{mm}$ on a $10-\mathrm{cm}$ visual analog scale. $78 / 122(63.9 \%)$ children entered the OLE. The mean(SD) IFX dose at wk 196 was $4.4(1.6) \mathrm{mg} / \mathrm{kg}$. IFX was well-tolerated; $14.1 \%$ of patients discontinued due to adverse events (AE) from wks 52-204. The distribution/types of AE were similar to those in the first 52 wks \& no new safety issues were reported. Among the 36 study patients by wk 204, ACRPedi-30/50/70/90 responses were 91.7\%(33/36), $83.3 \%(30 / 36), 69.4 \%(25 / 36)$, \& 50\%(18/36), respectively. 39\%(14/36) of patients achieved remission. From wk 52 through wk 216,36.6\%(26/71) of patients were positive for IFXantibodies; $57.7 \%(15 / 26)$ of these had an infusion reaction. Continuous IFX+MTX administered up to 4 yrs was safe \& effective in JRA patients, although accompanied by a high rate of patient discontinuation, which included subjects in remission. 